\title{
Educating Culturally Responsive Han Teachers: Case Study of a Teacher Education Program in China
}

\author{
Huanshu Yuan \\ Texas A\&M University \\ U. S. A.
}

\begin{abstract}
This qualitative case study examines how a teacher education institution in China prepares culturally responsive Han teachers for diverse student populations. The purpose of this study was to explore preservice Han teachers' perspectives of, and academic preparation in, multicultural education in order to enhance institutional quality and effectively prepare culturally responsive Han teachers for multicultural and multiethnic students in China. Four major findings revealed teacher candidates' ambiguous perceptions of diversity; the inadequate academic preparation in teaching for diversity; disparity between academic training and teaching practice; and lack of institutional commitment to preparing teachers for diversity in China.
\end{abstract}

KEYWORDS: multicultural education, teacher preparation, culturally responsive pedagogy, multicultural teacher education, China

\author{
Review of Related Research \\ Methodology \\ Findings \\ Conclusion \\ References \\ Author Contact
}

The People's Republic of China is a multiethnic, multilingual, and multicultural country, governed by a single party government led by the Communist Party (Leibold \& Chen, 2014). China is also the world's most diverse country represented by 56 different ethnic groups. Along with the social transformation and urbanization processes, the number of minorities has been increasing, especially in metropolitan cities, since the Chinese government started enabling the migration of people for both economic development and the improvement of individual living standards (Iredale, Bilik, \& Guo, 2003; Wu, 2008).

Despite the central government's concerns, ethnic minorities are often linked to biased cultural representation and stereotypical images in mainstream society (Wang, 2015; Zhao, 2007). Many from the ethnic majority group, called "Han," still hold deficit attitudes toward non-Han groups and "label them as barbarians" (Zhao, 2007, p.4). This historically rooted stereotype has negative influences on the cultural representations and educational experiences of minorities in mainstream society, whereas the ethnic majority Han culture is represented as valued, modern, and normal. Under the efforts of balancing 
national unity and ethnic diversity, the state education system seeks to transform its goal of achieving ethnic harmony as a more "complex reality" (Leibold \& Chen, 2014; Wang, 2015). Educational curricula and policies are designed to cultivate the shared sense of national belongingness by establishing specially designed programs that target both ethnic minority and Han majority citizens (Leibold \& Chen, 2014).

The supply of adequately trained teachers is crucial to successful educational outcomes for ethnic minority students. Sato (2014) pointed out that China has experienced a history of concentrating resources in the eastern part of the country so that its education system is experiencing an unbalanced growth in urban centers in contrast to the rural west. In recent years, many ethnic minority students have moved for the purpose of getting better education. This desire for high quality education in urban areas has led to a higher rate of migration from rural minority regions to urban Han residency areas (Iredale, Bilik, \& Guo, 2003).

In addition to the many ethnic minority students moving for the purposes of education throughout the whole of China, particular groups of ethnic minority secondary school students also move to cities, such as Beijing and Shanghai, to study outside their underdeveloped residency regions (Geng, 2013). This is particularly the case for Tibetan and Uygur students who migrate to Beijing to attend higher quality schools. The "Inland Tibetan Class" and "Xinjiang Class" have been established to accept more Tibetan and Uygur students from the middle school level to post-secondary education (Geng, 2013; Leibold \& Chen, 2014). The mass scale of migration from rural western inland to urban eastern coastal cities is changing the ethnic demographics of education in China. The influx of migrant ethnic minority students and the increasing number of second-generation ethnic minorities in urban areas create challenges for majority Han teachers who are used to having only Han students in their classrooms.

This societal context necessitates an examination about how Han teachers are prepared to handle the changing demographic reality of their classrooms. This study was designed to explore preservice Han teachers' perspectives of, and academic preparation in, multicultural education in order to enhance institutional quality and effectively prepare culturally responsive Han teachers for multicultural and multiethnic students in China.

\section{Review of Related Research}

Competent teachers are essential to improving the quality of education for students. An important goal of their professional teacher education is to prepare teachers to better serve diverse student populations (Gay, 2018; Guyton \& Wesche, 2005). Inadequate training in students' cultures, learning styles, and communication patterns may result in negative assumptions and expectations, use of culturally inappropriate or insensitive materials, and negative student-teacher interactions (Gay, 2018; Wallace, 2000). The following bodies of research and 
theory inform this study, offering different but related perspectives on preparing teachers to be culturally responsive to ethnically and racially diverse students.

\section{Teacher Attitudes}

Teacher attitudes towards students are enacted in academic environments, teaching practice, curriculum design, and interpersonal relationships. An important factor that results in minority students' lower academic achievements is negative teaching attitudes and stereotypical expectations towards their cultural and racial identities.

A related set of research on teacher attitudes focuses more specifically on how cultures are implicated in overt and covert racism present in preK-12 schools. This, too, influences how minority students encounter and engage with academic learning environments. Cultural racism in the United States (sometimes referred to as hegemony) refers to the "elevation of the White Anglo-Saxon Protestant cultural heritage to a position of superiority over the cultural experiences of ethnic minority groups" (Gay, 2018, p.33). The legacy of cultural racism is found in formal mainstream curricula, textbooks, mass media, and course offering. Gay also argued that it is embedded in hidden, informal curricula such as racial myths and stereotypes held by students and teachers. Negative teacher attitudes and beliefs toward racial minority students create an unfamiliar, unsupportive, and unfriendly academic environment, reduce academic motivations, and demean student selfesteem and cultural identity.

Research from scholars in China also indicates that teachers' attitudes and beliefs are significantly associated with minority students' self-confidence, identity construction, and academic outcomes (Geng, 2013; Lv, 2014; Ming, 2013). For example, Qian (2007) reported that minority parents often complain about the local school and the teachers. The study concluded with this observation from one participant:

Minority children aren't being well taught in school, and they're losing their self-confidence because teachers think they are not smart enough. Our kid has never been considered as a good learner, and the minority language our kid speaks is also considered as too backward. (p.66)

To become effective with all of their future students, teachers and teacher candidates need to develop a better sense of themselves and "develop a sense of their students' experiences as well" (Darling-Hammond, 2002, p.204), along with subject matter content and pedagogy. Understanding and respecting racial, ethnic, and cultural diversity should be an essential component of teacher preparation. It is essential for teacher education programs to enable teachers to understand teaching as an intellectual and cultural activity, as well as develop productive perspectives about interactions among race, culture, class, and schooling. 


\section{Cultural Knowledge and Culturally Responsive Pedagogy}

In addition to teacher attitude, it is critical for teachers to gain cultural competence about their students. This competence involves teachers in acquiring and using culturally diverse knowledge to be able to design culturally relevant curricula, instructional strategies, and learning environments (Kunjufu, 2002). Some cultural knowledge can only be gained from the cultural contexts of their work. Since culture is essential to student learning, teachers must become knowledgeable about their diverse students' distinctive cultural backgrounds so they can effectively translate that knowledge into more appropriate instructional techniques and curricula designs (Gay, 2018; Zeichner \& Payne, 2013).

Developing cultural knowledge also involves reducing prejudice and creating cross-cultural awareness. Melnick and Zeichner (1997) explained how cultural and historical knowledge can help prospective teachers overcome their "cultural ignorance of groups different from their own" (p. 29) and avoid stereotypic responses to diverse cultural groups. As their research findings indicate, it is important to assist teacher education students in learning how to learn about the students and the cultural communities from which their students come and in which they will teach in the future (Zeichner \& Payne, 2013).

Gay (2018) mentioned that teaching practices based on culturally relevant content and pedagogy can play an essential role in reducing institutional racism and achievement gaps, as well as improving minority students' self-esteem, identities, learning engagements, and academic outcomes. Culturally responsive pedagogy involves informing teaching content with diversity, equips dynamic instructional methods with academic rigor, develops equity within mainstream and students' cultural contexts, and focuses on improving academic outcomes for minority students (Banks, 2004; Gay, 2018).

Culturally responsive pedagogy provides guidelines for teachers to become "cultural mediators" (Sleeter \& Cornbleth, 2011), brokers who can demonstrate respect and caring for students as well as make subject matter content more accessible and meaningful for minority students (Gay, 2018). As such, culturally responsive teachers can and should act as cultural brokers (Lipka, 1998), cultural translators (Lomawaima, 2004), and warm demanders (Gay, 2018). As Gay (2018) indicates, culturally responsive pedagogy teaches to and through the strengths of multicultural students; it is "culturally validating and affirming" (p. 29). It is more than a means to improve minority students' standardized test scores. Most importantly, it can improve instructional quality by inspiring teachers from the majority group to be critically reflective about what they know about their students' knowledge backgrounds and cultural heritages and what conflicts might exist between their own cultural knowledge and that of their students. 


\section{Instructional Materials and Cooperative Learning}

Along with teacher attitude and pedagogy, teachers can also improve their teaching of culturally diverse students through effective integration of multicultural content and promotion of cooperative learning. Content integration is one of the essential components of multicultural education. According to Banks (2004), it deals with the extent to which teachers use examples, materials, data, and information from a variety of cultures and groups to illustrate key academic concepts, principles, generalizations, and theories in their subject areas or disciplines. Gay (2018) broadened the notion of instructional content and materials by arguing for the inclusion of culturally relevant components in curriculum design and learning materials. Moll and Gonzalez (2006) recommended using diverse students' funds of knowledge to improve their academic performance. This is the "knowledge base that underlines the productive activities of households" (p. 700). The concept can be broadened to universities' curricula and learning environments for prospective teachers. It also provides important pedagogical implications for changing current methods of teaching and altering the perceptions of diversity held by teachers in schools.

Scholars in China are becoming increasingly concerned about the effects of negative stereotypes of minority students' cultures and the lack of minority representation and knowledge in school curricula and textbooks (Chen, 2014; Jin \& Jin, 2016). For example, Hansen (1999) reported that for most Dai in Yunnan Province, state education has very little space for their ethnic identity, traditional values and knowledge, and culture. Scholars in China are calling for greater inclusion of minority cultures in the curriculum and instructional materials, to combat feelings of cultural inferiority and to develop pride in unique aspects of minority culture (Jin \& Jin, 2016; Wang, 2015). Minority students need to learn about mainstream language and culture, but mainstream Han students and teachers also need to learn more about the languages and cultures of various minority groups in China as well.

Inclusion of multicultural content also needs to be combined with effective instruction of the content. Effective learning for students calls for active interactions among culturally diverse peers and between students and teachers. Otherwise, inequities are likely to develop. For example, new migrant ethnic minorities arrive in Han-dominant classrooms in urban areas in China with varied educational experiences and Mandarin proficiencies, which lead to variation in their academic skills and performances. When minority students engage in cooperative group activities and positive interactions, they can pose interesting questions, exchange ideas, negotiate strategies on how to accomplish tasks, learn to resolve conflicts, and possibly reduce the achievement gap with their majority counterparts (Cohen \& Lotan, 2014; Gay, 2018).

Allport (1954) suggested that the support of teachers and school administrators, as well as positive equal-status relationships and interactions 
among students of all ethnic and racial groups, is vital to producing academic achievement. This finding has important implications for enhancing positive and inclusive classroom interactions. According to Gay (2018), teachers are important authority figures, who can facilitate positive interactions among minority students and their majority peers by using cooperative learning and alternative grouping strategies. Cooperative learning is a central feature of an equitable classroom, as well as a well-documented and highly recommended strategy for improving academic, cognitive, social, and attitudinal outcomes for students (Cohen \& Lotan, 2014; Gay, 2018). It can also promote linguistic and cultural pluralism in academic learning environments, as well as the identity development of minority students.

\section{Relationships with Communities}

Teaching in culturally responsive ways is both conceptual and practical, and encompasses ideologies, strategies, and relationships that teachers "enact in classrooms as they strive to accommodate the needs of students and challenge them intellectually, with rigorous content" (Grossman et al., 2008, p. 245). In order for preservice teachers to translate their knowledge of culturally responsive teaching into classroom practices, they need guidance and opportunities to do so under the tutelage of teacher educators. Specific learning experiences need to be designed especially for developing these skills, yet most White teacher candidates in the United States "have lived their lives within White communities and have lacked opportunities to learn firsthand about the cultures of people of color" (Villegas \& Lucas, 2002, p.154). Similar observations can be made about majority groups in other countries, such as the Han in China.

Noel (2013) described the concept of community strengths and urged teachers to "go into the community, meeting and partnering with community members and agencies, to learn about the important community strengths that can then be utilized in a more culturally relevant education" (p.137). Valuing and utilizing community strengths to facilitate students' learning also relates to the concept of "funds of knowledge," introduced by Moll and his colleagues (2006) who urged prospective teachers to develop contextualized understandings of culturally diverse families and communities so as to develop more authentic strategies for teaching ethnically diverse students. In fieldwork conducted by Bahry, Darkhor, and Luo (2013) in a minority district of China, there was broad support among parents and teachers, regardless of ethnicity, for greater local minority cultural content studied in schools. In an example such as this, teachers gained local knowledge and connected with the community. Ultimately the community connection would complete teachers' efforts for educating minority students effectively, which are built upon positive teacher attitude, relevant cultural knowledge, culturally responsive pedagogy, inclusion of cultural content, and cooperative learning. 


\section{Methodology}

This study used a qualitative case study approach, which included documents, two rounds of semi-structured interviews, and focus groups in a selected teacher education program in Beijing, People's Republic of China. In order to triangulate findings in this study, a variety of data were collected: e.g., curricular materials, course descriptions, assessment and evaluation forms, and learning materials for document analysis along with interview transcripts and participants' narrative stories. A "basic interpretive format" (Merriam, 2009) was designed and followed to understand the interaction of preservice teachers with the culture of the academic learning environment and school contexts in which they study and complete their student-teaching experiences. Qualitative research is a useful way to explore Han preservice teachers' views of their professional preparation and fieldwork experiences with respect to teaching ethnically and culturally diverse students; their understanding of ethnic and cultural effects on minority students' learning; and ways that their teacher education program incorporated knowledge, attitudes, and skills for culturally responsive teaching.

Purposeful sampling (Patton, 2002) was used to recruit information-rich participants for an in-depth study of a teacher education program in multicultural education and culturally responsiveness teaching in China. Based on the research purpose of identifying preservice Han teachers' perceptions of their teacher education programs' efficacy in preparing them to be culturally responsive teachers, the targeted study participants were Han teacher education students (called normal students) in a targeted normal university, called Central Normal University (pseudonym), in Beijing with experiences of teaching ethnic minority students.

The normal university was selected because it concentrates on training prospective K-12 teachers, instead of an institution that was more researchoriented and whose graduates mainly pursue advanced degrees in education and seek jobs such as school administrators. This university focused on prospective K-12 teacher preparation, in-service teacher training, post-service teacher development, teacher exchange and volunteering in rural and ethnic autonomous regions, and professional training for in-service ethnic minority teachers from Xinjiang.

Preservice teachers were selected from a range of different compulsory subjects taught in schools, including math, Chinese, English, science, and social science. It was important to have variation in the subjects preservice teachers taught; therefore, liberal arts and social science subjects such as Chinese, English, history, and politics were targeted for identifying participants. In addition to subject disciplines, teacher candidates were also selected based on their Han ethnic identity, four years of studying in a teacher education program, at least one year of student teaching experience, and experience with diverse student demographics in their student-teaching classes or schools. 
Another factor in the selection of preservice teacher participants was whether they had been involved in any other teaching experiences with minority students, such as Teach for China and other volunteer teaching programs in remote ethnic autonomous regions. Participants were expected to have some minority student teaching experiences in order to better demonstrate their understanding of how cultural and ethnic factors contributed to minority students' learning processes, outcomes, and their own future teaching success in multicultural and multiethnic school contexts. The five teacher education students (Yunxi, Jiayin, Yongqiao, Jin, and Nanqiao), selected as participants, included three females and two males. They were 22 to 23 years old. All were in the fourth year of college studies and four of the five taught in middle schools. All participants had experiences working with ethnic minority students, from volunteer teaching programs in ethnic minority regions (three participated in Teach for China, and two participated in summer volunteer teaching programs in Xinjiang) to student teaching practicums at placement schools with ethnically and culturally diverse student populations.

\section{Findings}

This case study exploration revealed four critical themes: (1) teacher candidates had ambiguous perceptions of diversity; (2) their teaching preparation for diverse students was inadequate; (3) the candidates experienced disparity between their academic preparation and teaching practice; and (4) the teacher education program lacked commitment to preparing teachers for diversity. Each theme is elaborated in the following sections.

\section{Ambiguous Perceptions of Diversity}

In order to capture teacher candidates' personal perceptions and knowledge backgrounds towards multiculturalism and teaching for diversity, all participants participated in the first round of focus group. At the focus group, they identified their personal beliefs and previous knowledge of diversity and ethnic minority groups and discussed their cultural awareness and instructional competence while teaching in diverse settings. All of the five teacher candidates mentioned the cultural erasure of minority groups during the process of national unity and the fact that social modernization had created an imagined picture of "others." The ambivalent feelings about diversity caused by globalization were also mentioned by the participants.

"What do we talk about when we talk about multiculturalism and diversity in China?" This question opened up the discussion about cultural globalization and cultural localization. The five teacher candidates' impressions and conceptions of multiculturalism consisted mainly of Western (especially U.S.) culture and Chinese culture. Yunxi said, "When we talk about multiculturalism, it is not 'multi' as it is 
supposed to be. In most cases it is more like biculturalism---Western and Chinese cultures." Most of the other teacher candidates agreed with the widespread "biculturalism" and the binary diversity created by this cultural paradigm. As Yunxi declared further, "I think the concept of multiculturalism is imported from the West, especially from the United States. This leads to the pervasive impact of Western culture on our conceptions and knowledge construction of diversity." Yongqiao agreed, adding, "We [do not] have a clear understanding of multiculturalism in China, because the concept of cultural diversity we are so familiar with is closely tied to the Western context."

The ambiguous perception and vague definition of multiculturalism narrowed the concepts of diversity and culture to visible diversity and distinctive culture, which created a visibility gap within China's context of multicultural education. Consequently, the split conceptions of diversity converted multicultural education in China into multi-ethnic education in ethnic autonomous regions. This conceptualization of culture and diversity affected the diversity awareness and formation of cultural knowledge of prospective teachers.

\section{Inadequate Academic Preparation in Teaching for Diversity}

The missions of teacher education programs play important roles in shaping teacher candidates' learning experiences and outcomes. The goals of Central Normal University teacher education focused on developing subject knowledge, instructional skills, and morality. After reviewing and analyzing the core curricula, course settings, and program completion requirement documents, it was determined that the cultural context of teaching and preparing teachers for diversity was not clearly mentioned in the mission of the programs.

The invisibility of the cultural context of teaching also limited teacher candidates' interests in cross-cultural and multicultural education. Although the teacher candidates in this study acknowledged the importance of developing cultural awareness and knowledge for teachers in multiethnic China, the university leadership did not consider cultural competence to be as important as subject competence. This resulted in cultural silence in the program mission in the target normal university's teacher education program; preparing teachers for diversity was regarded as related to individual interests. One of the teacher candidates, Yongqiao, argued that the cultural diversity awareness of teacher candidates, the location of teacher education institutions, and the academic interests of teacher educators greatly influenced the sensitivity and effectiveness of promoting culturally responsive teacher education. She said,

Because I am from Xinjiang, my living experience inspired my academic interests in multicultural education. Reflecting on my previous $\mathrm{K}-12$ experience, the Han teachers in our mixed-ethnicity schools do not have sufficient cultural understandings and knowledge of ethnic minority students. They are not equipped with teaching strategies that meet Uygur 
and other ethnic minority students' communication and learning styles. Moreover, many of them do not consider this is a big issue. So when I entered my teacher education program I specifically paid attention to classes that could introduce multicultural education theory and teaching practice for prospective teachers. However, it seemed that the significance of addressing diversity mainly connected to students or professors' personal and academic interests.

The traditional university-based teacher education curricula in China follow the Han-centric perspectives and focus on subject content knowledge and pedagogy (Jin \& Jin, 2016; Zheng, 2013). The curricula for pre-service teacher training at Central Normal University included general education, subject-content education, teacher education, and field-work education. These programs gave primary attention to the foundation of education in the candidates' subject majors.

The five teacher candidates mentioned the overemphasis on subject knowledge and the limited emphasis on sociocultural contexts of teaching. Jing said, "I don't think our programs address the issue of diversity and sociocultural context of teaching. Due to the commonly defined teacher competence as subject competence, the sociocultural impacts on teaching are usually ignored." Yunxi pointed out, "The majority of teacher candidates and teacher educators rarely pay attention to the issue of diversity and preparing teachers for diversity. They lack cultural or ethnic connections to minority groups and living experiences in diverse communities and cross-cultural environments."

Jiayin thought that the unequal distribution of subject courses, general educational courses, and teacher education courses failed to achieve the goal of improving teacher candidates' subject, educational, and emotional (interpersonal) competences. She stated, "The teacher education foundation and pedagogy courses are very limited and superficial compared to the subject content courses. The duration of teacher education courses is also packed into one academic year. This does not give us enough time to internalize educational theories into instructional practice."

The five teacher candidates in this study felt that their academic training did not increase their confidence in teaching diverse students or teaching in diverse school settings. This was due to the limited culturally relevant courses, lack of culturally responsive teacher educators, and insufficient teaching practices in diverse placements. Even after their normal school training, they felt their knowledge about globalized and marginalized indigenous people remained largely the same at their pre-university level. The five teacher candidates indicated they had acquired knowledge of cultural others mainly through self-learning, peer interactions, and collaboration with international and ethnic minority students' study groups and cultural clubs. Their development of cross-cultural understandings and multicultural knowledge was primarily attributed to their personal and informal interactions with ethnic minority students and groups, rather than from formal academic learning in classes. 


\section{Disparity between Academic Training and Teaching Practice}

The teacher candidates were not confident in their ability to teach diverse students or within diverse school contexts. Their major anxiety was a sense of uncertainty about approaching students from diverse cultural and ethnic backgrounds. Yunxi mentioned that "the cultural knowledge and ethnic traditions I learned from social interactions and elective courses were superficial and could hardly transform into my teaching strategies." Jiayin agreed that the academic training in teaching for diversity was inadequate in building connections with diverse students and adjusting to the school environment. Nanqiao highlighted that the limited living and teaching experiences in diverse communities provided by the academic studies and practicum "did not diversify the Han-led social and cultural environments at schools."

Communication difficulties in the culturally and ethnically diverse regions caused the teacher candidates to engage in critical reflections on linguistic impacts on education. Differences between Mandarin and indigenous ethnic languages and local dialects created communication barriers that reduced their instructional effectiveness in local schools. None of the teacher candidates could speak local dialects and ethnic languages. This created obstacles for interactions with their students and local teachers.

The five teacher candidates reported difficulties in building relationships in the areas of trust with students, cooperation with local teachers, and connection with the local community. The difficulty of connecting with different cultural and ethnic backgrounds was shocking to Jing. He attributed this to being accustomed to ethnic minority people learning Mandarin and adapting to Han culture, especially in urban areas. He explained:

Language was the first challenge. None of us [volunteer teaching participants] could speak and understand the Uygur language. We took for granted that there were no communication obstacles since we still taught inside China. But the Mandarin proficiencies of local students and teachers were not as good as we expected, so misunderstandings happened a lot.

Yunxi associated the difficulties in connecting with students to the shifting role of teachers. She said,

In urban schools teachers are authority figures. Students simultaneously respect us and follow our instruction. There are no visible cultural differences and language barriers in communicating and teaching. But in volunteer teaching schools, the co-existence of cultural differences and linguistic diversity challenged our teaching attitudes and strategies. We were no longer authority figures for local students. More often we were viewed as visitors.

According to Yongqiao, inadequate cross-cultural knowledge and experience between Han and Uygur teachers expanded this cultural and 
understanding gap. She recalled an incident in which a Uygur teacher felt Han volunteer teachers thought their own culture was superior to Uygur culture. This perception created an unequal relationship between Han and Uygur teachers. Lack of assistance from supervisory teachers also increased the difficulties for teacher candidates to engage in local school environments. Jiayin explained this situation when she said, "Our leading teacher and cooperating teachers at the target school did not provide us with sufficient instructions and advice in adapting to the local cultural and school environments. This made our efforts to cooperate with local teachers more difficult."

\section{Lack of Institutional Commitment to Preparing Teachers for Diversity}

All five teacher candidates suggested that more equal emphasis should be placed on developing cultural competence in their preservice education program. They identified several issues that might hinder institutional effectiveness in preparing Han teachers for diversity. First, the national curriculum, which did not prioritize diversity and multiculturalism, was identified as one of the major obstacles to the professional development of multicultural education in China. The Ministry of Education creates common curriculum and instructional goals for teacher education throughout the country. The national unified standards, institutional missions on subject matter education, and teacher educators' limited multicultural competencies jointly posed challenges for preparing teachers for diversity in China.

Second, efforts to develop prospective teachers' cultural competence were mostly achieved by adding elective courses, creating multicultural guest lectures and seminars, organizing volunteer teaching and teacher exchange programs, and relying on teacher educators' efforts to interweave relevant issues into their educational foundation and pedagogy classes. However, those efforts were mainly focused on theoretical research, not actually on its implementation into required program curricula and academic training processes. As the sociocultural aspects of teaching are missing from the core curricula and required courses, it is harder for teacher candidates to actually develop this cultural awareness and competence.

Moreover, faculty resistance and lack of policy reinforcement also hindered efforts to develop multicultural teachers. Similar resistances were reported by LV (2014). In his study of Chinese teacher education programs, he noted they did not enhance teachers' cultural awareness, challenge the cultural deficit teaching concept, embrace multicultural education courses, or offer teacher-mentoring and field work training for developing Han teachers' culturally responsive pedagogies. Consequently, in-service and preservice teachers at normal universities usually were not interested in exploring ways to improve teaching effectiveness for diverse student population. Lv argued that Chinese educational institutions encounter "lacking of relevant [national] laws and regulations concerning education excellence and equity for ethnic minorities" (p.105). 


\section{Conclusion}

The findings from this study revealed that the preparation of culturally responsive Han teachers did not receive sufficient attention in the urban teacher education institution. The university-based teacher education program examined in this research approached teaching for diversity only through adding elective courses, providing guest lectures and educational seminars, and diversifying the placements for volunteer-teaching programs. A variety of studies that focused on multicultural education theory in China raised similar concerns.

For example, Geng (2013) questioned how to convert multicultural theories into practice under the Chinese educational system. Jin and Jin (2016) noted that despite attention to situating multicultural education into China's context, theoretical and conceptual ideas had not been implemented very well in preservice and in-service teacher development programs. Most Han teachers did not understand cultural influences on teaching and learning and know how to respond to the needs of diverse students in multicultural schooling environments. These claims were confirmed by the results of this study and suggest that it is important to raise the multicultural awareness of teacher candidates, in-service teachers, and teacher educators in China. While teacher candidates in this study acknowledged the significance of ethnic minority culture and Western culture, they stressed that their acceptance of the existence of various cultural heritages and ethnic diversities was not transformed into teaching strategies before and after entering in teacher education programs.

The findings of this study also revealed that conceptions of multiculturalism in China tend to have a rather narrowly substantive focus, limited to ethnic minority groups within minority autonomous regions in China. While this is quite common, it is inconsistent with current theoretical characterizations of multicultural education in both China and other countries such as the United States. As Wang (2015) pointed out, cultural diversity and cultural sensitivity should not be limited to ethnically diverse groups in ethnic minority regions. This approach neglects multicultural awareness and cultural competence in urban areas and urban teacher education institutions. Wang and Gou (2012) suggested that the development of multicultural competence needs to include both regional characteristics and national emphases. The teacher candidates in this study endorsed these ideas. While Yongqiao and Jing, who had multicultural living experiences, advocated for valuing indigenous cultures and languages, others (Jiayin, Yunxi, and Nanqiao) showed hesitancy and uncertainty when addressing ethnic diversity in urban areas. Although all teacher candidates expressed their faculty's commitment to developing courses and activities that help introduce multicultural education concepts and teaching strategies to prospective teachers, the actual development of these curricula and related competences for teacher candidates was not occurring at a sufficient level to establish qualified multicultural education. 
Very few studies on Chinese multicultural teacher education have been conducted from Han perspectives. This study points out the importance of preparing cultural and ethnic majority (Han) teachers to acquire multicultural knowledge and cross-cultural teaching competences for improving ethnically diverse, rural, migrant, and globalizing education in China. It also expands the understanding of how mainstream Han teachers and teacher education programs in urban areas can be more responsive to and effective for ethnically, racially, culturally, and economically diverse student populations. The results offer guidance for creating a pathway to establishing school cultures and academic environments within teacher education programs where "students of every cultural and racial background feel welcome and are encouraged to reach their highest potential, as well as receive academic achievements" (Bennett, 2004, p.864).

\section{References}

Allport, G. W. (1954). The nature of prejudice. Boston, MA: Addison-Wesley.

Bahry, S., Darkhor, P., \& Luo, J. (2009). Educational diversity in China: Responding to globalizing and localizing forces. In G. A. Wiggan \& C. B. Hutchison (Eds.), Global issues in education: Pedagogy, policy, practices, and the minority experience (pp.103-130). Lanham, MA: Rowman \& Littlefield.

Banks, J. A. (2004). Handbook of research on multicultural education ( $2^{\text {nd }}$ ed.). San Francisco, CA: Jossey-Bass.

Bennett, C. I. (2004). Research on racial issues in American higher education. In J. A. Banks \& C. A. M. Banks (Eds.), Handbook of research on multicultural education (2 ${ }^{\text {nd }}$ ed., pp. 847-867). San Francisco, CA: Jossey-Bass.

Chen, Y. (2014). Towards another minority education elite group in Xinjiang. In J Leibold \& Y. Chen (Eds.), Minority education in China: Balancing unity and diversity in an era of critical pluralism (pp. 201-220). Hong Kong, China: Hong Kong University Press.

Cohen, E. G., \& Lotan, R. A. (2004). Equity in heterogeneous classrooms. In J. A. Banks \& C. A. M. Banks (Eds.), Handbook of research on multicultural education ( $2^{\text {nd }}$ ed., pp.736-752). San Francisco, CA: Jossey-Bass.

Darling-Hammond, L., French, J., \& Garcia-Lopez, S. (2002). Learning to teach for social justice. New York, NY: Teachers College Press.

Gay, G. (2018). Culturally responsive teaching: Theory, research and practice. New York, NY: Teachers College Press.

Geng, L. (2013). Reflection on multicultural education under the background of globalization. Higher Education Studies, 3(6), 53-57.

Grossman, P., McDonald, M., Hammerness, K., \& Ronfeldt, M. (2008). Dismantling dichotomies in teacher education. In M. Cochran-Smith, S. Feiman-Nemser 
\& D. J. Mclntyre (Eds.), Handbook of research on teacher education $\left(3^{\text {rd }}\right.$ ed., pp.243-248). New York, NY: Routledge.

Guyton, E. M., \& Wesche, M. V. (2005). The multicultural efficacy scale: Development, item selection, and reliability. Multicultural Perspectives, 7(4), 21-29.

Hansen, M. H. (1999). Lessons in being Chinese: Minority education and ethnic identity in Southwest China. Seattle, WA: University of Washington Press.

Iredale, R., Bilik, N., \& Guo, F. (2003). China's minorities on the move: Selected case studies. New York, NY: M. E. Sharp.

Jin, H., \& Jin, S. (2016). Study on multicultural education qualities in Chinese ethnic universities: Taking the pre-service teachers of Yanbian University as an example. US-China Education Review, 6(9), 542-547.

Kunjufu, J. (2002). Black students, middle class teachers. Sutton, United Kingdom: Reed Business Information.

Leibold, J., \& Chen, Y. B. (2014). Minority education in China. Hong Kong, China: Hong Kong University Press.

Lipika, J. (1998). Transforming the culture of schools: Yup'ik Eskimo examples. Mahwah, NY: Lawrence Erlbaum.

Lomawaima, K. T. (2004). Educating Native Americans. In J. A. Banks \& C. A. M. Banks (Eds.), Handbook of research on multicultural education $\left(2^{\text {nd }}\right.$ ed., pp.441-460). San Francisco, CA: Jossey-Bass.

Lv, Y. (2014). Multicultural education in Chinese schools: What lessons from the British experience. Comprehensive Journal of Educational Research, 2(6), 104-110.

Melnick, S. L., \& Zeichner, K. M. (1997). Enhancing the capacity of teacher education institutions to address diversity issues. In J. E. King, R. E. Hollins, \& W. C. Hayman (Eds.), Preparing teachers for cultural diversity (pp. 2339). New York, NY: Teachers College Press.

Merriam, S. B. (2009). Qualitative research: A guide to design and implementation. San Francisco, CA: Jossey-Bass.

Ming, H. (2013). The education of migrant children and China's future: The urban left behind. Hoboken, NJ: Taylor \& Francis.

Moll, L., \& Gonzalez, N. (2006). Engaging life: A funds-of-knowledge approach to multicultural education. In J. A. Banks \& C. A. M. Banks (Eds.), Handbook of research on multicultural education ( $2^{\text {nd }}$ ed., pp. 319-348). San Francisco, CA: Jossey-Bass.

Noel, J. (2013). Moving teacher education into urban schools and communities: Prioritizing community strengths. New York, NY: Taylor \& Francis.

Patton, M. Q. (2002). Qualitative research and evaluation methods. Thousand Oaks, CA: Sage. 
Qian, M. (2007). Ethnic education should undertake the major historic task of ethnic unity and the possibility of and explorations into the localization of diversified education. Chinese Education and Society, 43(5), 62-76.

Sato, M. (2014). What is the underlying conception of teaching of the edTPA? Journal of Teacher Education, 65(5), 421-434.

Sleeter, C., \& Cornbleth, C. (2011). Teaching with vision: Culturally responsive teaching in standards-based classrooms. New York, NY: Teachers College Press.

Villegas, A., \& Lucas, T. (2002). Preparing culturally responsive teachers: $A$ coherent approach. Albany, NY: State University of New York Press.

Wallace, B, C. (2000). A call for change in multicultural training at graduate schools of education: Educating to end oppression and for social justice. Teachers College Record, 102(6), 1086-1111.

Wang, G. (2015). Ethnic multilingual education in China: A critical observation. Educational Linguistics, 30(2), 35-47.

Wang, Y., \& Gou, S. (2012). Implications and inspirations from multicultural teacher education in the United States. Teacher Education Research, 24(5), 85-91.

$\mathrm{Wu}, \mathrm{X}$. (2008, May). The household registration system and rural-urban educational inequality in contemporary China. Presented at the International Sociological Association, Research Committee on Social Stratification and Mobility Meeting. Florence, Italy.

Zeichner, K., \& Payne, K. (2013). Democratizing knowledge in urban teacher education. In J. Noel (Ed.), Moving teacher education into urban schools and communities: Prioritizing community strengths (pp. 3-19). New York, NY: Taylor \& Francis.

Zheng, H. (2013). Teachers' beliefs and practices: A dynamic and complex relationship. Asian-Pacific Journal of Teacher Education, 41(3), 331-343.

Zhao, Z. (2007). Am I privileged? Minority Mongol students and cultural recognition in Chinese universities. Retrieved from http://dx.doi.org/10.5353/ th_b3783126

\section{Author Contact}

Huanshu Yuan: hsyuan@tamu.edu

Texas A \& M University, 400 Bizzell Street, College Station, Texas 77843, USA 